\title{
48
}

\section{Der Beginn des Lebens (Suchrätsel)}

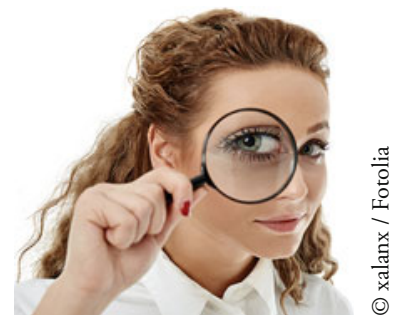

Finde alle unten stehenden Begriffe im Suchrätsel. Die verbleibenden Buchstaben ergeben (Zeile für Zeile gelesen) das achtstellige Lösungswort.

Hinweis Die Begriffe sind von links nach rechts oder von oben nach unten zu lesen - nie diagonal oder rückwärts.

ACTIN - ALLELE - ATP - BLAUWAL - BOR - CAUDAL - CDNA CELLULOSE - CESTODA - DENS - DNA - EPIDEMIE - HCV HIV - KERN - LAC - MUS - TEMPERATUR - TENTAKEL RADULA - RNA - RODENTIA - THC - ZINK - ZNS

\begin{tabular}{|c|c|c|c|c|c|c|c|c|c|c|}
\hline T & K & A & C & T & I & N & K & B & O & R \\
\hline E & P & I & D & E & M & I & E & L & A & C \\
\hline M & D & E & N & M & U & S & R & A & C & E \\
\hline P & N & I & A & H & I & V & N & U & E & S \\
\hline E & A & C & A & U & D & A & L & W & L & T \\
\hline R & O & D & E & N & T & I & A & A & L & O \\
\hline A & M & E & B & R & N & A & L & L & U & D \\
\hline T & E & N & T & A & K & E & L & A & L & A \\
\hline U & H & S & Z & I & N & K & E & T & O & A \\
\hline R & Z & N & S & H & C & V & L & H & S & T \\
\hline N & R & A & D & U & L & A & E & C & E & P \\
\hline
\end{tabular}

Lösung:

(C) Springer-Verlag Berlin Heidelberg 2016 C. Reinbold, Fetthenne, Moderlieschen, Warzenbeißer, DOI 10.1007/978-3-662-52817-4_48 